\title{
Análisis urbano ambiental del espacio litoral del municipio de Coveñas en el departamento de Sucre - Colombia
}

\author{
Environmental urban analysis of coastal space in the municipality of Coveñas in the \\ department of Sucre, Colombia
}

\author{
Oscar Guevara Guevara, ${ }^{1}$ Esp; Diana Sevilla Torres, $^{2}$ Ph.D. \\ ${ }^{1}$ Corporación Universitaria del Caribe - CECAR. Sincelejo, Colombia. Correspondencia: oscar. \\ guevara@cecar.edu.co. \\ ${ }^{2}$ Corporación Universitaria del Caribe - CECAR. Sincelejo, Colombia. Correspondencia: diana. \\ sevilla@cecar.edu.co.
}

Recibido: 9 de abril de 2016. Aceptado: 15 de octubre de 2016

Guevara, O.; Sevilla, D. (2016) Análisis urbano ambiental del espacio litoral del municipio de Coveñas en el departamento de Sucre - Colombia. Procesos urbanos Número 3, Ene-Dic. 99-107. Doi:10.21892/2422085X.270

\section{RESUMEN}

El presente artículo realiza una descripción y análisis de la localización y características del espacio litoral del municipio de Coveñas en el departamento de Sucre, Colombia. A partir de este análisis se pudo identificar y explicar los problemas urbanos y ambientales que padece este espacio litoral. Dentro de estos problemas, se destacan: la Inaccesibilidad a los bordes costeros, la alta densidad de segundas residencias en zonas de potencial uso turístico, la alta densidad de zonas construidas frente a manglares, las falencias en el sistema de alcantarillado, las inundaciones, el inadecuado uso de los arroyos y, sobre todo, las inexactitudes del sistema de planificación territorial. Es así como se expone la "solución" aplicada por los actores públicos y privados para los problemas urbanos ambientales de Coveñas, la cual consiste, únicamente, en la construcción de obras para contrarrestar la erosión de las costas, dejando de lado los demás problemas que afectan al municipio. Se puede afirmar que no se han adoptado, ni se prevén soluciones para minimizar los problemas que aquejan al municipio y a la comunidad. Lo que se pretende con este análisis es plantear soluciones, desde la planificación territorial, para disminuir los problemas descritos con antelación, para demostrar cómo, desde las falencias en la planificación territorial, se deriva un compendio de problemas que pone en juego la riqueza natural, el potencial turístico y el bienestar de la población de este municipio.

Palabras clave: Coveñas, Sucre, Colombia, sistema de planificación territorial, oportunidades urbano-ambientales.

\section{ABSTRACT}

The present article makes a description and analysis of the location and characteristics of the coastal space of the municipality of Coveñas in the department of Sucre, Colombia. From this analysis, it was possible to identify and explain the urban and environmental problems that this coastal area has. These problems include inaccessibility to coastal edges, high density of second residences in areas of potential tourist use, high density of built-up areas in front of mangroves areas, sewer system failures, floods, inadequate use of the streams and, above all, the inaccuracies of the territorial planning system. This is how public and private actors apply the "solution" for the urban

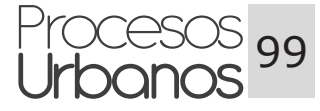




\section{Procesos Urbanos Nº 3 Enero - Diciembre; 2016}

environmental problems of Coveñas, which only consists in the construction of works to counter the erosion of the coasts, leaving aside the other problems that affect the municipality. It can be affirmed that solutions have not been adopted, nor are they foreseen to minimize the problems that afflict the municipality and the community. The aim of this analysis is to propose solutions, from territorial planning; to reduce the problems described in advance, to demonstrate how, from the shortcomings in territorial planning, a compendium of problems derives that puts in play the natural wealth, the tourist potential and the well-being of the population of this municipality.

Keywords: Coveñas, Sucre, Colombia, territorial planning system, urban-environmental opportunities.

\section{INTRODUCCIÓN}

En el análisis urbano ambiental del espacio litoral que comprende al municipio de Coveñas se detectaron problemas relacionados con la inaccesibilidad a los bordes costeros, la alta densidad de segundas residencias en zonas con potencial uso turístico, la alta densidad de zonas construidas frente a manglares, las inundaciones y el inadecuado uso de los arroyos, las falencias en el sistema de alcantarillado y sobretodo, las fallas en el sistema de planificación territorial ya que existen tres planes los cuales son: el Plan Básico de Ordenamiento Territorial 2006 del municipio de Coveñas (PBOT), el Plan de Manejo Integrado de la Unidad Ambiental Costera Estuarina del Río Sinú y Golfo de Morrosquilllo (PMIZC) y el Plan de Ordenamiento y Manejo de las Cuencas Hidrográficas Caribe y San Jorge en la jurisdicción de "CARSUCRE" (POMCH), $y$ ninguno de ellos ofrece herramientas adecuadas para planificar el territorio objeto de estudio.

Desafortunadamente no existen estudios confiables sobre las problemáticas enunciadas, ya que solo se cuenta con información contemplada en los planes elaborados, pero tal información es deficiente. Lo que se sabe de los problemas, como por ejemplo las obras que se realizan para afrontar la erosión, se logró determinar por medio de observación en el lugar y noticias periodísticas.

El área de estudio de la presente investigación se encuentra en el municipio de Coveñas, ubicado en Colombia al noreste del departamento de Sucre, pertenece a la sub-región del golfo de Morrosquillo, entre las coordenadas geográficas a los $9^{\circ} 21^{\prime}$ 100 Urocesos $00^{\prime \prime}$ y $9^{\circ} 27^{\prime} 00^{\prime \prime}$ de latitud norte y los $75^{\circ}$ $37^{\prime} 00^{\prime \prime}$ y $75^{\circ} 37^{\prime} 00^{\prime \prime}$ de longitud al oeste de Greenwich, con una altura de 2 metros sobre el nivel del mar; la precipitación promedio anual es de $1.200 \mathrm{~mm}$, y comprende un territorio cuyo relieve es plano en cercanías de la llanura costera aluvial y de serranías que forman los límites con el departamento de Córdoba, los municipios de Purísima y San Antero. (Concejo municipal de Coveñas, 2008, p.3).

La temperatura media es de $30^{\circ} \mathrm{C}$. (Alcaldía de Coveñas - Sucre, 2014), según el diagnóstico del PBOT, el clima lo determina la influencia de la Zona de convergencia intertropical se presentan dos periodos; uno seco que va de mediados de diciembre hasta marzo, con vientos alisios del norte, y uno lluvioso que se inicia en abril cuando se logran los más altos valores de pluviosidad en octubre y disminuyen hacia noviembre. Los meses de mayo, junio y julio son considerados como de transición entre los dos periodos principales. (Parra, 2009, p.8). Con relación a la hidrología, las aguas superficiales identificadas principalmente por arroyos, caños y ciénagas componen todo el sistema del municipio, con un comportamiento hídrico similar, de enero a julio se secan los cauces secundarios y terciarios, mientras que de septiembre a noviembre los caudales se tornan significativos aun cuando esto sea de carácter temporal.

La cuenca principal existente en Coveñas es la del golfo de Morrosquillo, la cual se encuentra conformada por los municipios de Coveñas y de Tolú. Las microcuencas se encuentran y desembocan en el área del golfo de Morrosquillo, se denominan de la siguiente forma: microcuenca ciénaga de la Caimanera, microcuenca 
arroyo Amansaguapo, microcuenca arroyo Remanguenaguas y microcuenca arroyo $\mathrm{EI}$ Silencio. (Concejo municipal de Coveñas, 2008, p.86)

La flora se encuentra caracterizada por el Caracolí (Anacardium excelsum), Matarratón (Gliricidia sepium), guásimo (Guazuma ulmifolia) Ceiba Tolú (Bombacopsis quinata), naranjuelo (Capparis odorotissima), Olla de mono (Lecythis magdalenica), Totumo (Crescentia cujete), Samán (Samanea saman) y la Zarza (Mimosa pigra). En el golfo de Morrosquillo se encuentran las cuatro especies de Mangle de las familias rhizophoraceace, avicenniaceae, combretaceae, que corresponden en su orden a Rhizophora mangle (Mangle rojo), Avicennia germinans (Mangle negro), Laguncularia racemosa (Mangle blanco) y la Conocarpus erectus (Mangle zaragoza). Por su parte la ciénaga de La Caimanera, se encuentra bordeada en su totalidad por una franja, en algunos casos hasta 1000 metros de las especies rhizophora mangle (dominante), seguida por avicennia germinans, laguncularia racemosa y conocarpus erectus. Asociada al L. racemosa, se encuentra el helecho Matatigre A. aureum. El golfo de Morrosquillo presenta una serie de unidades de cobertura vegetal íntimamente ligadas a las condiciones climáticas e hidrológicas de la región. Esto conlleva a la presencia de determinados tipos de cobertura vegetal tales como vegetación de tipo xerofítica (con cactáceas) e higrofítica, con desarrollo de bosques semidecicuos, arbustales caducifolios, praderas (predominantemente herbáceas, arbustivas y arbóreas), vegetación de pantano y bosques de manglar. (Concejo municipal de Coveñas, 2008, p.87)

Según datos del "Censo general, resultados ajuste censal a junio 30 de 2005" del DANE, el municipio contaba con un total de 11.331 habitantes, de los cuales se asentaban en la cabecera municipal 3.121 y 8.210 en otros corregimientos. El censo 2007 del SISBEN arrojó un número mayor de habitantes con un total de 12.211. El cálculo de turistas en el plan de desarrollo 2008 - 2011 es de 30.000 personas y desciende al $5 \%$ en temporada baja, y para los casos de la mayoría de cabañas es de $0 \%$. La Base Militar que se emplaza en el municipio cuenta con 7.000 a 5.000 hombres contados como población flotante del municipio. (Concejo municipal de Coveñas, 2008, p.24).

El PBOT del municipio de Coveñas contiene la definición de las clasificaciones del suelo en: urbano, de expansión urbana y rural. De igual forma determinó suelos de protección de acuerdo con lo establecido en la Ley 388 de 1997. La extensión total es de 7414 Km2, la extensión del área urbana es de $2214 \mathrm{Km} 2$ y la del área rural es de $5200 \mathrm{Km} 2$. (Alcaldía de Coveñas - Sucre, 2014).

Adicional a esta clasificación existe una zonificación ambiental, la cual orienta los usos de zonas como playas públicas, lagunas costeras, manglares, forestal protector, forestal productor, asentamiento indígena etnia zenú, zonas agrícolas, recreacional, turística del corredor de la playa, urbana, marítima de pesca, veda de pesca industrial y áreas de producción económica sostenible. De algunas de estas zonas solo se asignan nombres y otras tienen una localización específica y cartografiada.

Asimismo, el PBOT determina usos bajo la clasificación de: uso principal, uso complementario, uso restringido y uso prohibido. Como normas urbanísticas generales define: densidades, áreas mínimas de lotes, retiros, índice de ocupación, índice de construcción, alturas, voladizos y cerramientos. (Concejo municipal de Coveñas, 2006).

\section{Diagnóstico de problemas urbano ambientales}

A continuación se presenta una descripción de los problemas urbanos ambientales más representativos de la situación actual del espacio litoral del municipio de Coveñas, el origen de algunos de esos problemas y un análisis a las propuestas y soluciones para contrarrestar los problemas identificados en la zona objeto de estudio que se han implementado por parte de entes públicos, privados o por parte de la misma comunidad. 


\section{Alta densidad de segundas residencias en zonas con potencial uso turístico.}

Actualmente la alta densidad de segunda residencia ocupa y limita el acceso a las zonas con mayor potencial turístico. Los pescadores que originalmente ocupaban estas zonas fueron desplazados, lo cual hace difícil su acceso al mar. Esta forma de ocupación del suelo no genera empleo y por esta razón no es equiparable con el turismo, ni equiparable lo que retribuyen al municipio pues son estrato tres. Estas construcciones obstruyen la comunicación natural entre mar y manglares contribuyen al deterioro de estos ecosistemas y favorecen la alta división predial por las presiones del mercado inmobiliario (Figura 1).

El origen de este problema es antrópico, que desencadena un mercado inmobiliario sin control. Las directrices aplicadas facilitan su proliferación al no hacer objeto de tratamiento especial las zonas paralelas a la línea costera y la estratificación facilita su existencia.

Los espacios naturales más afectados son zonas aledañas a los bordes costeros como manglares y campos de dunas, lo cual también afecta a los habitantes de Coveñas.

Entre las soluciones que se han adoptado en los diferentes planes territoriales no se prevé un mecanismo que permita regular la alta densidad de segundas residencias en zonas de potencial uso turístico.

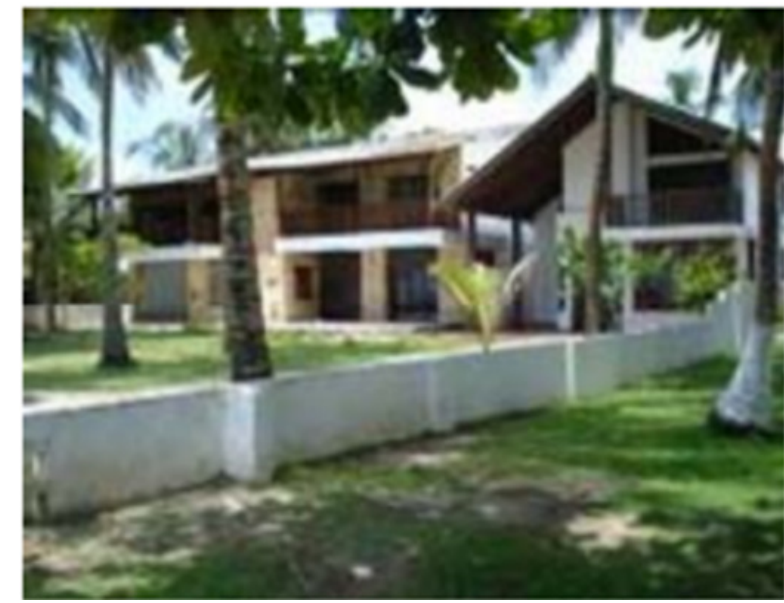

Figura 1. Imágenes donde se percibe la alta densidad de segundas residencias en zonas con potencial uso turístico.

Fuente: Parra (2009)

\section{Inaccesibilidad a borde costero}

El borde costero es un espacio considerado como bien de uso público. En la actualidad y en la zona de estudio, estos espacios son inaccesibles, lo que impide su aprovechamiento para el ocio y recreación, adicionalmente limitan las actividades de quienes trabajan en el mar, como por ejemplo los pescadores (Figura 2).

El origen del problema es antrópico. Se observan deficiencias en la atención a la planificación vial, y las directrices aplicadas no contemplan accesos. El espacio afectado específicamente son las playas de Coveñas, que involucran y afectan directamente a la población raizal y a los turistas. Según
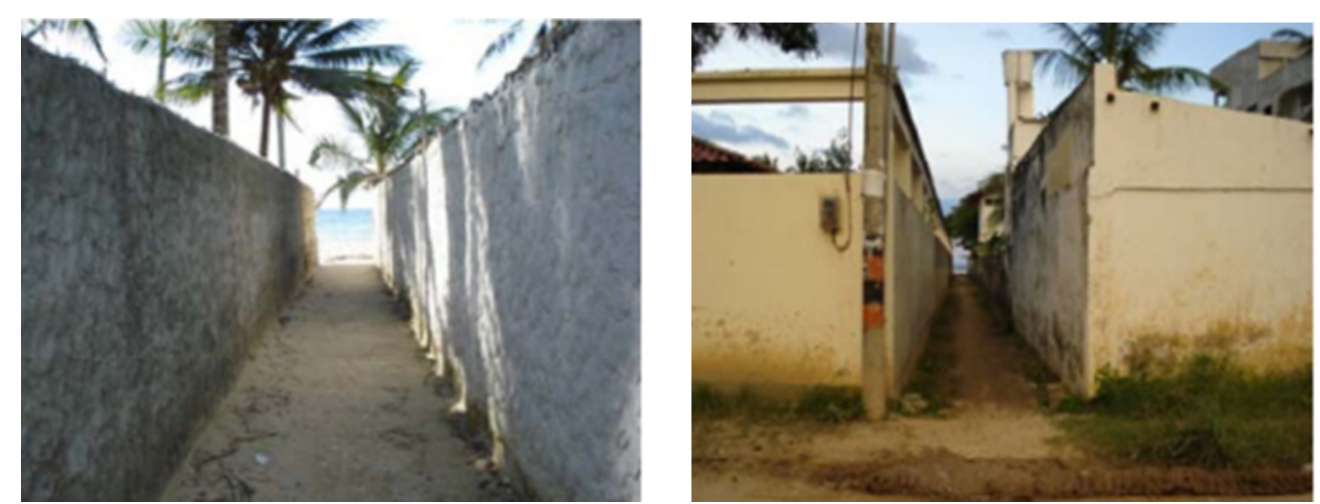

Figuras 2. Imágenes donde se aprecia el alto grado de inaccesibilidad a los bordes costeros del municipio de Coveñas. Fuente: Parra (2009) 
Guevara,O. y Sevilla, D. - Análisis urbano ambiental del espacio litoral de Coveñas, Colombia.

el PBOT del municipio de Coveñas, como solución al problema se establece una zonificación ambiental y una normativa que pretende regular el uso del borde costero. (Concejo municipal de Coveñas, 2006). Sin embargo, esta zonificación ambiental y una normativa no son una solución adecuada para la problemática en cuestión.

\section{Alta densidad de zonas construidas frente a manglares}

La alta densidad de ocupación sobre el suelo genera la incomunicación entre el mar y las aguas de los arroyos que alimentan estos manglares. Otro asunto preocupante en estas zonas es el manejo de residuos sólidos y el vertimiento de aguas de alcantarillado, que se hace directamente al manglar o con pozos que no tienen los cuidados necesarios en su elaboración. Esta situación ha deteriorado principalmente los manglares de Isla Gallinazo (Figura 3).

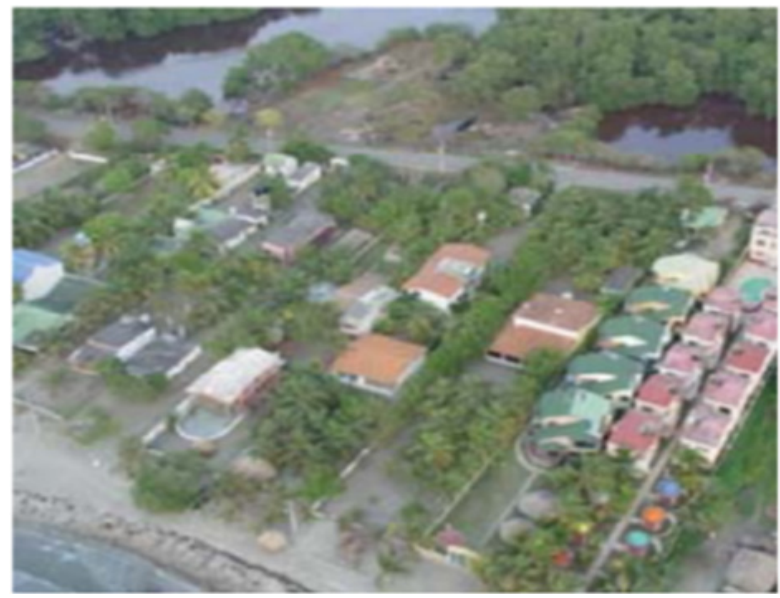

Figura 3. En la imagen se aprecian amplias zonas construidas frente a manglares.

Fuente: CARSUCRE (S.F.)

El origen del problema es antrópico. Las directrices aplicadas facilitan aumento de densidades entre manglares y borde costero, y no regulan formas de construcción que permitan el intercambio de aguas dulces y saladas. Se puede decir que no existen estudios sobre formas de construcción menos "densas" que se adapten a los flujos de intercambio entre aguas dulces y saladas para la subsistencia de los manglares.
El espacio afectado específicamente son los ecosistemas de manglares que afecta directamente a la población de Coveñas. Según el PBOT, se establece como solución determinar una zonificación ambiental, normativas y proyectos para contrarrestar los efectos que han causado las zonas construidas frente a los manglares. (Concejo municipal de Coveñas, 2006).

\section{Inundaciones e inadecuado uso de los arroyos}

Las construcciones de obras que involucran los arroyos cambian los caudales de estos y sus regímenes sedimentarios. Esto puede tener consecuencias sobre las coberturas vegetales de las cuencas, la turbidez del agua de mar, las playas y manglares y también sobre los arrecifes de corales del golfo de Morrosquillo, lo que perjudica futuramente actividades como la pesca y el turismo, en el caso de que los aportes de sedimentos lleguen a afectar las playas.

De igual manera la falta de control sobre estas intervenciones en los arroyos, puede incidir sobre las inundaciones que estos ocasionan afectando las actividades agrarias y a los pobladores. Al referirse a inundaciones, en el año 2012, hay registros de inundaciones en el municipio de Coveñas por el desbordamiento del arroyo Amansaguapo, que dieron como resultando 300 familias afectadas. (Figura 4).

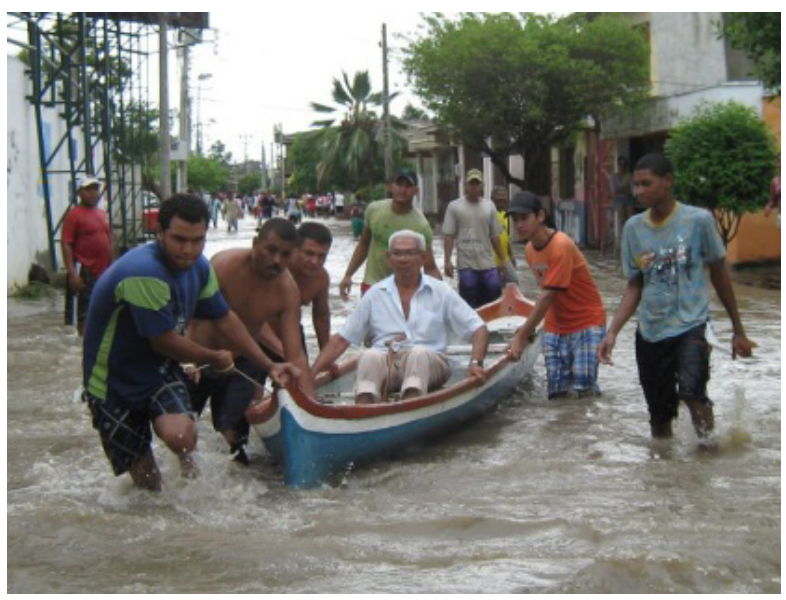

Figura 4. Inundación en el municipio de Coveñas en el año 2012.

Fuente: Quiñonez (2012) 
El origen del problema es antrópico. Esta actividad se desarrolla sin control. Existen vacíos en las directrices aplicadas y falta de estudios técnicos sobre las relaciones de las dinámicas de las microcuencas y las zonas costeras.

El ecosistema de playas es el principal espacio afectado y este a la vez está relacionado con la afectación de los ecosistemas de manglares, los ecosistemas de corales, las cuencas de los arroyos y los arrecifes de corales. La población, el turismo y los turistas también se ven afectados por dicha situación.

Se puede afirmar que al revisar los diferentes planes como el PBOT, PMIZC y POMCH, no se aprecian soluciones que permitan enfrentar la problemática descrita con anterioridad.

\section{Falencias en el sistema de alcantarillado}

Las aguas negras sin tratamiento, vertidas directamente a los arroyos, los contamina. Estos contaminantes pueden fácilmente llegar hasta el mar, situación agravada por los cortos recorridos de los arroyos hasta el mar. La contaminación en los manglares puede afectarlos y de paso disminuir la capacidad de producción de peces. Esta mala práctica, puede contaminar las aguas subterráneas.

Las letrinas sin pozos sépticos, terminan llevando las aguas contaminadas al mar, aguas superficiales de arroyos, aguas subterráneas y a los manglares.

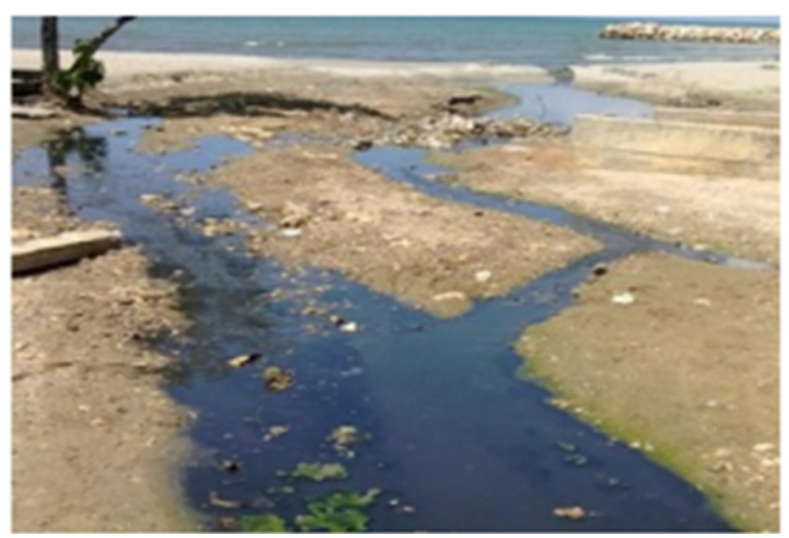

Figura 5. Aguas negras inundan viviendas y desembocan en el mar en una playa de Coveñas. Fuente: Caracol radio (2014)

104 Procesos
El origen del problema es antrópico. Se observa una falta de estudios de los manglares de la zona como depuradores de aguas negras. Deficiencias en la prestación del servicio. Se afectan recursos como las aguas marinas, aguas subterráneas, ecosistemas de manglares y las cuencas de los arroyos. Entre las personas o grupos afectados se encuentran los habitantes y turistas.

De nuevo, se puede afirmar que al revisar los diferentes planes como el PBOT, PMIZC y $\mathrm{POMCH}$, no se aprecian soluciones que se puedan adoptar para hacerle frente a la problemática descrita.

\section{Soluciones que se han adoptado o se prevén adoptar para la problemática}

En torno a la información descrita, se puede establecer que para las problemáticas del acceso al borde costero y de las segundas residencias, solo se percibe una zonificación y una serie de normativas en el PBOT de Coveñas que pretenden regular el uso del suelo, pero que en la actualidad no se aplican. Así mismo, no se contemplan acciones, programas ni proyectos en los diferentes planes revisados que propendan por soluciones al problema descrito.

En ese orden de ideas, en el PBOT de Coveñas se establece una zonificación ambiental, normativas y proyectos para contrarrestar la problemática que ha generado la proliferación de zonas construidas frente a los manglares, sin embargo por la falta de un buen proceso de implementación, seguimiento y evaluación en la gestión del plan, todo ha quedado en el papel y los manglares cada día se están deteriorando más. De acuerdo con lo anterior, cabe resaltar la importancia de los manglares en el ambiente, Farguell \& Barriocanal (2015) establecen que: Los manglares son unos de los ecosistemas litorales con más riqueza biológica y capacidad de producción de biomasa. Forman unas masas boscosas con especies capaces de vivir en el agua marina, y destacan la importancia de estos ecosistemas como protectores de la zona costera. 
En torno a las inundaciones y el uso de los arroyos, no se perciben acciones, programas ni proyectos que permitan contrarrestar dicha problemática. En ese sentido, el municipio de Coveñas carece de estudios encaminados a medir el consumo doméstico, para tener un estimativo de la cantidad de agua contaminada que se debe tratar para no seguir contaminando el entorno. Es importante entender el concepto de consumo doméstico, por lo tanto, Farguell et al. (2015) afirman que: "Por consumo doméstico se entiende el agua que llega a los hogares, se bebe y se usa de manera que parte de ella vuelve al medio pero contaminada, y debe tratarse para poderse volver a usar".

Como se ha establecido, en el municipio de Coveñas se han registrado inundaciones, en ese orden de ideas, resulta trascendental la definición del concepto de inundación y entender porqué se producen. De acuerdo con Farguell et al. (2015) "las inundaciones se producen porque las aguas fluviales "salen" de su cauce principal y ocupan áreas llanas adyacentes al cauce. Se llaman inundaciones porque al ocupar esos terrenos dañan y perjudican lo que haya plantado o construido en esas áreas". Para la problemática del alcantarillado, no se perciben acciones, programas ni proyectos que permitan contrarrestar la problemática descrita.

Respecto a la problemática de la erosión, se percibe la construcción de obras para hacerle frente a dicho problema. Aunque las obras realizadas fueron ejecutadas por actores públicos y privados, se aprecia que estas no se contemplan en los planes revisados, razón por lo cual se estima que han sido soluciones no planificadas para atender los serios problemas de erosión que presentan las costas de la zona de estudio.

En síntesis, para la gran mayoría de los problemas descritos no existen soluciones desde los diferentes planes formulados para la zona objeto de estudio, ni se han realizado acciones, ya sea por parte de entes públicos, privados o por la misma comunidad, para afrontar las problemáticas existentes, solo se han construido elementos para contrarrestar el problema de la erosión, pero como se indicó, son soluciones no planificadas juiciosamente y por lo tanto son poco eficientes. De igual manera, es preocupante la situación que afronta la zona de estudio, en la cual se han formulado tres planes (PBOT, PMIZC y POMCH), pero solo el PBOT contempla algunas soluciones (que se quedaron en el papel) a los problemas diagnosticados, mientras que los otros planes solo llegan a la fase diagnóstica, razón por la cual no ofrecen acciones, programas ni proyectos para contrarrestar las problemáticas.

Para atender de manera eficiente las problemáticas descritas anteriormente se propone la elaboración de un plan que maneje de manera integral los problemas que afronta el municipio de Coveñas. Un plan que contemple las tres fases expuestas por Gómez (2002) las cuales son: análisis territorial, planificación territorial y gestión territorial, y no planes inconclusos que solo le sirve a un pequeño grupo del municipio para captar los recursos que el Estado colombiano brinda a los municipios que elaboran dichos planes.

Se debe elaborar un plan en el que la participación de diversos entes y de la comunidad se haga presente en toda la fase de elaboración e incluso en la fase de gestión del mismo. De esta manera y según lo expresado por Gómez (2002), se concibe un plan con credibilidad.

Adicionalmente, la fase de gestión debe contener un programa de implementación, seguimiento y evaluación eficiente que permita evaluar la aplicación del plan y llevar a la realidad las propuestas contempladas en este. En ese sentido, Benabent (2007) establece que la gestión del plan se suele considerar como el mecanismo que permite poner en marcha las propuestas contempladas en este, por ende esta fase debe estar bien armada si se quiere hacer factible lo que el plan propone. De ello dependerá que determinados contenidos puedan llevarse a cabo o por el contrario queden arrumados.

Para finalizar, se invita a la clase política de Sucre, Colombia y a su comunidad, aplicar

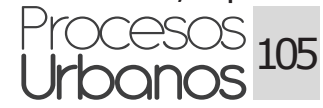


la siguiente reflexión aportada por Indovina (2004): "Planificar hoy también significa afrontar los problemas inmediatos; es políticamente irresponsable y técnicamente inconsistente dejar los problemas del presente para el futuro" (p.2)

\section{Conclusiones}

Se concluye que el principal problema que padece el espacio litoral del municipio de Coveñas es la inexactitud presentada en la planificación territorial en la cual se evidencia la falta de originalidad de los planes territoriales que toman como base de otros planes realizados en diferentes municipios sucreños, sin tener en cuenta el contexto del municipio de Coveñas. Es así como, de no realizar un trabajo de planificación territorial en el cual se diagnostiquen realmente los problemas territoriales y se planteen acciones contundentes para erradicar esa serie de falencias, se continuará poniendo en riesgo la riqueza natural, el potencial turístico y el bienestar de la población que habita en dicho territorio.

De acuerdo con el diagnóstico realizado y presentado en este documento, es relevante plantear de manera urgente un plan integral que sirva como carta de navegación para solucionar las situaciones problemáticas que actualmente aquejan a Coveñas. Un plan que contemple realmente un proceso de gestión que sea viable, y que no quede como uno de los tantos documentos archivados que solo sirven para satisfacer los requerimientos impuestos por las leyes de ordenamiento territorial del país.

\section{Referencias}

Alcaldía de Coveñas - Sucre (2014): Nuestro municipio. Información general. Disponible en http://www.covenas-sucre.gov.co/informacion general.shtml\#geografia

Benabent M. (2007): Los planes de ordenación del territorio en España. De la instrumentación a la gestión. Málaga: FUNDICOT.

Caracol Radio (2014). Emergencia sanitaria en Coveñas por colapso de alcantarillado. Disponible en http://caracol.com.co/radio/2014/09/08/regional/1410151200 403999.html

Concejo municipal de Coveñas (2006): Plan básico de ordenamiento territorial del municipio de Coveñas. Disponible en http://cdim.esap.edu.co/BancoMedios/Documentos\%20PDF/ cove $\%$ C3\%B1assucrepbot2006.pdf

Concejo municipal de Coveñas (2008): Plan de desarrollo económico social y de obras públicas para el municipio de Coveñas 2008 - 2011 "un mar de ideas". Disponible en http://cdim.esap. edu.co/BancoMedios/Documentos\%20PDF/3.\%20plan\%20de\%20desarrollo\%20\%202.0082.011\%20definitivo.pdf

Corporación Autónoma Regional de los Valles del Sinú y del San Jorge (2009): plan de ordenamiento y manejo de las cuencas hidrográficas Caribe y San Jorge en la jurisdicción de "CARSUCRE". Disponible en http://www.ambientalex.info/normasnal/ Resolucioncarvssj3452de2009.pdf

El Espectador (2012): Al menos 300 familias afectadas por inundaciones en Coveñas. Disponible en http://www.elespectador.com/noticias/nacional/al-menos-300-familiasafectadas-inundaciones-covenas-articulo-364879

El Meridiano (2015). Erosión en 41 kilómetros. Disponible en http://elmeridiano.co/erosionen-41-kilometros/8511 
Guevara,O. y Sevilla, D. - Análisis urbano ambiental del espacio litoral de Coveñas, Colombia.

Farguell \& Barriocanal (2015): Diapositivas de la asignatura planificación de espacios fluviales y litorales. Barcelona: Universidad de Barcelona.

Gómez O. (2002): Ordenación territorial, Ediciones Mundi- Prensa. Madrid.

Indovina, F. (2004): ¿Por qué el planeamiento hoy?. Territorio y ciudad, (17), 1 - 5.

INVEMAR, CVS, CARSUCRE, Ministerio del Medio Ambiente (2002): formulación del plan de manejo integrado de la unidad ambiental costera estuarina del río Sinú y golfo de Morrosquillo, informe técnico fase I caracterización y diagnóstico. Disponible en http://www.invemar.org. co/redcostera1/invemar/docs/uacmorrosquillo.pdf

Parra, E. (2009): Ordenamiento territorial costero en el Caribe colombiano. Las directrices del Estado en los casos de estudio de Coveñas y San Andrés. Universidad Nacional de Colombia, Medellín, Colombia.

Quiñonez, O. (2012). Tragedia invernal en Sucre. Disponible en https://www.google.com. $\mathrm{co} /$ search?q=inundacion +en+el+municipio + de + cove $\% \mathrm{C} 3 \% \mathrm{~B} 1 \mathrm{as} \& \mathrm{rlz}=1 \mathrm{C} 1 \mathrm{GGGE}$ esCO704CO704\&espv $=2 \&$ biw $=1920 \&$ bih $=973 \&$ source $=$ Inms\&tbm $=$ isch\&sa $=X \& v e d=0$ ahUKEwis8ci13svOAhXIMyYKHet4AB0Q AUIBygC\#tbm=isch\&q=inundacion+en+el+municipio+de+cove $\%$ C3\%B1as+en+el+2012\&imgrc $=\mathrm{H} 29 \mathrm{t} 1 \mathrm{EdixY7xVM \% 3 \textrm {A }}$ 